\title{
Comportamento microestrutural e de fluência do Inconel 718 após tratamento térmico de duplo envelhecimento
}

\author{
Fabricia Assis Resende Gonçalves ${ }^{1}$ \\ Renata Jesuina Takahashi ${ }^{1}$ \\ Danieli Aparecida Pereira Reis ${ }^{1 *}$ (1)
}

\section{Resumo}

Inconel 718 é uma liga à base de níquel que é principalmente utilizada em aplicações de alta temperatura devido às propriedades mecânicas e à tolerância a condições severas de trabalho. As ligas Inconel podem ter suas propriedades mecânicas melhoradas com a aplicação de tratamentos térmicos pela precipitação de fases endurecedoras. Neste trabalho objetivou-se estudar do comportamento mecânico e microestrutural da superliga Inconel 718 após ensaio de fluência. Comparou-se os resultados da liga sob as condições homegeneizada (como fornecida) e após tratamento térmico de duplo envelhecimento composto pelas etapas de solubilização $\left(1095^{\circ} \mathrm{C}\right.$ durante 1 hora) e tratamento térmico $\left(955^{\circ} \mathrm{C} / 1 \mathrm{~h}\right.$ seguido por $720^{\circ} \mathrm{C} / 8 \mathrm{~h}$ e $620^{\circ} \mathrm{C} / 8 \mathrm{~h}$ ). Os ensaios de fluência foram realizados no modo de carga constante de $625 \mathrm{MPa}$ e a temperatura em 650,675 e $700{ }^{\circ} \mathrm{C}$. Os corpos de prova de fluência foram avaliados pelas técnicas de caracterização de difratometria de raios $\mathrm{X}$, microscopia eletrônica de varredura e análise de dureza. Os resultados obtidos indicaram que as amostras que sofreram o tratamento térmico de duplo envelhecimento apresentaram maior resistência mecânica devido, possivelmente, a precipitação de fases endurecedoras como a fase $\gamma^{\prime}\left(\mathrm{Ni}_{3} \mathrm{Al}\right)$ e fase $\gamma^{\prime \prime}\left(\mathrm{Ni}_{3} \mathrm{Nb}\right)$ formadas durante $\mathrm{o}$ tratamento térmico da liga. Além disso, o ganho de resistência foi comprovado pelo aumento dos valores da dureza e pelo aumento no tempo de fratura dos ensaios de fluência.

Palavras-chave: Inconel 718; Tratamento térmico de duplo envelhecimento; Fluência.

\section{Creep and microstructural behavior of Inconel 718 after double aging heat treatment}

\begin{abstract}
Inconel 718 is a nickel-based alloy that is mainly used in high-temperature applications due to its mechanical properties and tolerance to severe work environments. Inconel alloys can be their mechanical properties significantly improved with the execution of heat treatments to precipitate hardening phases. This work aimed to study the mechanical and microstructural behavior of the Inconel 718 superalloy after creep test. The results of the alloy were compared under homogenized conditions (as received) and after heat treatment of double aging composed by solubilization $\left(1095{ }^{\circ} \mathrm{C}\right.$ for 1 hour) and heat treatment $\left(955^{\circ} \mathrm{C} / 1 \mathrm{~h}\right.$ followed by $720^{\circ} \mathrm{C} / 8 \mathrm{~h}$ and $\left.620^{\circ} \mathrm{C} / 8 \mathrm{~h}\right)$. The creep tests were executed in in the stress range of $625 \mathrm{MPa}$ in a constant load mode at 650,675 and $700^{\circ} \mathrm{C}$. The creep specimens were evaluated using X-ray diffraction, scanning electron microscopy and hardness analysis techniques. The results indicated that the samples of heat treated showed greater mechanical resistance, possibly due to the precipitation of hardening phases such as the $\gamma^{\prime}\left(\mathrm{Ni}_{3} \mathrm{Al}\right)$ and $\gamma "\left(\mathrm{Ni}_{3} \mathrm{Nb}\right)$, phases formed during the double aging heat treatment. In addition, the strength gain was proven by the increase in hardness and the increase in fracture time of creep tests.
\end{abstract}

Keywords: Inconel 718; Double aging treatment; Creep.

${ }^{1}$ Laboratório de Comportamento Mecânico de Metais, Instituto de Ciência e Tecnologia, Universidade Federal de São Paulo, UNIFESP, São José dos Campos, SP, Brasil.

*Autor correspondente: danieli.reis@unifesp.br 


\section{Introdução}

O comportamento de ligas metálicas durante deformação em temperaturas elevadas é complexo e varia de acordo com os parâmetros de processamento termomecânicos e com as condições de trabalho [1-3]. Sob o aspecto da engenharia, o fenômeno de fluência apresenta particular interesse para condições que possam levar à deformações substanciais, em componentes que operam em altas temperaturas, em espaços de tempo próximos da expectativa de vida útil do material [4-6]. Materiais capazes de suportar condições de trabalho severas são de grande importância, por exemplo, no projeto de turbina de avião, na indústria de energia, nuclear e petroquímica. As superligas são um exemplo de material desenvolvido para suportar tais exigências [7].

A superliga Inconel 718 é uma superliga endurecida por precipitação, contendo em sua composição elementos como alumínio, titânio e nióbio que podem levar à precipitação de uma fase secundária durante um tratamento térmico apropriado com objetivo de aumentar a resistência mecânica [8,9]. Um dos tratamentos térmicos utilizados para esse fim é o duplo envelhecimento, tratamento térmico que é possível obter devido a capacidade da Inconel 718 precipitar mais de uma fase endurecedora [4,7-9]. Devido ao elevado custo desse tipo de material, a execução de tratamentos que otimizam sua vida útil, atuando em sua integridade estrutural, diminuindo custos com manutenção e maximizando o fator de segurança são justificados. Tratamentos térmicos de envelhecimento, na Inconel 718, promovem o endurecimento por precipitar compostos intermetálicos como as fases $\gamma^{\prime}$ e $\gamma^{\prime \prime}$, sendo esta última a principal fase endurecedora da liga atuando como agente fundamental no mecanismo de bloqueio de discordâncias e promovendo aumento na resistência mecânica da liga [5,8-12].

Estudos sobre a superliga Inconel 718 submetida a tratamentos térmicos a altas temperaturas ainda são limitados e requerem maior investigação. Desta forma, este trabalho tem por objetivo estudar o comportamento mecânico e microestrutural da superliga Inconel 718 submetida a tratamento térmico de duplo envelhecimento sob ensaio de fluência.

\section{Materiais e métodos}

As amostras de Inconel 718 foram obtidas na Villares Metals S.A. e seis corpos de prova (cdps) para o ensaio de fluência foram usinados de acordo com ASTM E139-06 [13]. Sob a mesma norma [13], foram realizados os ensaios de fluência em fornos em atmosfera ao ar pertencentes ao Instituto Tecnológico de Aeronáutica (ITA) com tensão constante de $625 \mathrm{MPa}$ e em três diferentes temperaturas: 650,675 e $700{ }^{\circ} \mathrm{C}$. Os cdps foram submetidos ao ensaio de fluência sob duas condições: conforme recebido e após tratamento térmico de duplo envelhecimento, condições denominadas no trabalho por AR e DA, respectivamente.

Para realização do tratamento térmico utilizou-se o forno refratário da marca Lindberg / Blue, pertencente ao Departamento de Engenharia de Materiais da Escola de Engenharia de Lorena (DEMAR / EEL-USP). O tratamento térmico seguiu a literatura $[14,15]$ em que os cdps foram encapsulados em tubo de quartzo a vácuo e a atmosfera de argônio, e o tratamento de solução sólida iniciou-se a $1095{ }^{\circ} \mathrm{C}$ por 1 hora, seguido pelo tratamento de duplo envelhecimento que foi realizado em três etapas: a $955^{\circ} \mathrm{C}$ por $1 \mathrm{~h}$ para precipitar a fase $\delta$, a $720^{\circ} \mathrm{C}$ por $8 \mathrm{~h} \mathrm{e} 620^{\circ} \mathrm{C}$ por $8 \mathrm{~h}$ para precipitar as fases $\gamma^{\prime}$ e $\gamma^{\prime \prime}$, como mostrado na Figura 1. A obtenção das fases $\gamma$ ' e $\gamma$ "' foram responsáveis pelo endurecimento do material e pela dissolução de fases deletérias e carbonetos na matriz segundo os autores [11,16,17].

As microestruturas do Inconel 718 antes e após o duplo envelhecimento foram analisadas por Microscopia Eletrônica de Varredura, MEV, (Quanta FEI 650) pertencente ao Laboratório Nacional de Nanotecnologia do Centro Nacional de Pesquisa em Energia e Materiais (LNNano/ CNPEM). A análise microestrutural dos cdps ocorreu a partir

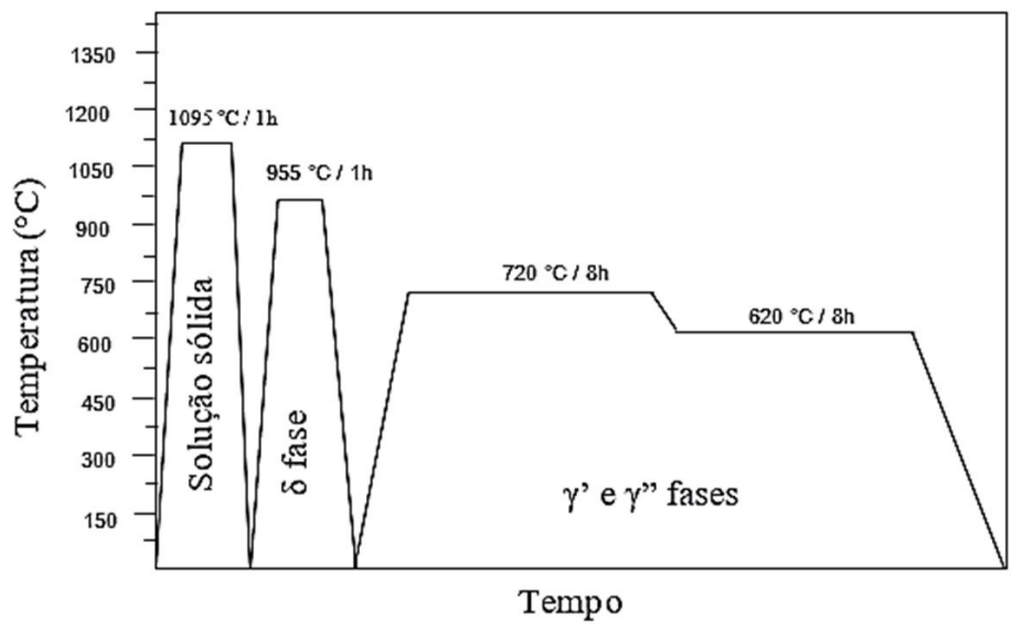

Figura 1. Etapas realizadas para tratamento térmico de duplo envelhecimento. Adaptado de Feng et al. [15]. 
de cortes nas direções transversais e longitudinais, seguindo os padrões usuais de metalografia, com embutimento a quente e lixamento com lixas à base de $\mathrm{SiC}$, na sequência de 600,1200 e 2400 mesh. O polimento foi realizado com pasta de diamante de $1 \mu \mathrm{m}$. As amostras foram submetidas ao ataque eletroquímico com ácido oxálico $10 \%$.

Para obtenção das medidas de microdureza foi utilizado um microdurômetro Futere-Tech FM-700, instalado no Instituto de Estudos Avançados (IEAv) com carga de $100 \mathrm{gF}$ durante 30 segundos. O resultado foi a média de 5 indentações em cada amostra, com uma distância média de $20 \mu \mathrm{m}$ entre cada impressão ao longo da seção transversal da amostra.

As análises de difratometria de raios $\mathrm{X}$ (Rigaku Ultima IV), foram realizadas a temperatura ambiente sob radiação $\mathrm{Cu}-\mathrm{K} \alpha$, com filtro de níquel (sem monocromador). Com passo angular de 0,02 graus e o tempo de contagem de 15 segundos.

\section{Resultados}

A Tabela 1 mostra a relação dos principais parâmetros de fluência para o mesmo valor de tensão (625 MPa). O valor de $\mathrm{t}_{\mathrm{p}}$ é relativo ao tempo primário (estágio primário de fluência); $\dot{\varepsilon}_{S}$ taxa de fluência (estágio secundário de fluência); $\mathrm{t}_{\mathrm{f}}$ é o tempo final da fratura, e $\varepsilon_{\mathrm{f}}$ corresponde à deformação da fratura. Também são deduzidos os valores de redução em área (RA). Conforme observado na Tabela 1 , as amostras com o tratamento de duplo envelhecimento apresentaram maiores resistência em relação às amostras sem tratamento nas mesmas temperaturas de ensaio. Observou-se um padrão de aumento dos valores de $\mathrm{t}_{\mathrm{p}}, \mathrm{t}_{\mathrm{f}} \mathrm{e} \varepsilon_{\mathrm{f}}$ e diminuição na $\dot{\varepsilon}_{s}$ promovendo uma redução na velocidade de deformação por fluência com a aplicação de tratamento de duplo envelhecimento. Essa diminuição na taxa secundária de fluência implicou no aumento de resistência, uma vez que a diminuição da taxa secundária propiciou a redução na taxa de velocidade de deformação do material, promovendo maior tempo de vida, cuja tendência no comportamento em fluência também foi reportada por autores [3,5]. Esses fatores indicaram um aumento na resistência à fluência da liga após o tratamento térmico de duplo envelhecimento, que ocorreu pela precipitação de fases endurecedoras, como as fases $\gamma^{\prime}$ e $\gamma$ ", devido ao seu alto valor energético de contorno de fase [8]. Essa alta energia dificultou a mobilidade dos deslocamentos, portanto, foi necessário aplicar uma tensão maior para superar essa barreira [14]. Observou-se que o tratamento térmico de duplo envelhecimento promoveu aumento na resistência, aumentando a vida em fluência da superliga Inconel 718. Tal aumento também foi relatado por Kuo et al. [14]

Observou-se, pelos valores de RA (Tabela 1), que as amostras na condição de DA apresentaram redução na ductilidade. Tal efeito foi mais uma evidência da precipitação de fases endurecedoras. A redução de área do cdps, em uma avaliação macroscópica da fratura da fluência, foi realizada para descrever as características das rupturas conforme mostra a Figura 2.

As amostras AR em $650^{\circ} \mathrm{Ce} 675^{\circ} \mathrm{C}$ (Figuras $2 \mathrm{a}$ e $2 \mathrm{~b}$, respectivamente) mostram a fratura dúcteis, enquanto a amostra AR a $700{ }^{\circ} \mathrm{C}$ (Figura 2c), assim como as amostras DA em todas as temperaturas de ensaio (Figuras 2d, 2e, 2f), apresentaram a fratura dúctil-frágil, onde duas regiões com características distintas de fratura foram evidentes.

As amostras AR demonstraram uma tendência de fratura com características dúcteis (estrutura taça-cone), apresentando o desenvolvimento de uma região central fibrosa com microcavidades ou dimples de formato equiaxial e de pouca profundidade, e de uma região chamada de zona de cisalhamento, com inclinação de aproximadamente $45^{\circ}$ em relação a tensão aplicada, além da presença de precipitados distribuídos pelos alvéolos. Esses precipitados são possivelmente carbonetos dispersos na matriz [18]. No entanto, na condição mais severa, Figura 2c, amostra AR em $700{ }^{\circ} \mathrm{C}$ e $625 \mathrm{MPa}$, as imagens mostraram características de fratura mista (dúctil-frágil) com duas regiões distintas de fratura. As fractografias (Figuras 2d, 2e, 2f) após fluência das amostras DA demostraram uma tendência de fratura com características dúctil-frágil, na qual a porção da fratura caracterizada por fratura frágil apresentou micromecanismo de fratura intergranular, formada por trincas intergranulares e presença de facetas. Já a porção caracterizada por fratura dúctil apresentou micromecanismo dominante de fratura alveolar, com formação de dimples equiaxiais não profundos, no entanto, em menor porção quando comparado ao homogeneizado.

As características de fratura frágil foram acentuadas na superliga Inconel 718 na condição DA, possivelmente, devido a presença dos precipitados de fases endurecedoras, como: fases $\gamma^{\prime} \mathrm{e} \gamma^{\prime \prime}$. Em todas as amostras com tratamento de

Tabela 1. Parâmetros de fluência.

\begin{tabular}{ccccccc}
\hline $\mathbf{T}\left({ }^{\circ} \mathbf{C}\right)$ & Amostra & $\mathbf{t}_{\mathbf{p}}(\mathbf{h})$ & $\dot{\varepsilon}_{S}(\mathbf{1} / \mathbf{h})$ & $\mathbf{t}_{\mathbf{f}}(\mathbf{h})$ & $\boldsymbol{\varepsilon}_{\mathbf{f}}(\mathbf{m m} / \mathbf{m m})$ & $\mathbf{R A}(\mathbf{\%})$ \\
\hline $\mathbf{6 5 0}$ & AR & 48,0 & $8,80 \times 10^{-6}$ & 480,0 & 0,253 & 43,2 \\
& DA & 56,0 & $1,98 \times 10^{-6}$ & 426,0 & 0,026 & 2,17 \\
$\mathbf{6 7 5}$ & AR & 20,0 & $4,57 \times 10^{-5}$ & 115,0 & 0,075 & 39,7 \\
& DA & 34,0 & $1,30 \times 10^{-5}$ & 206,0 & 0,027 & 3,30 \\
\multirow{2}{*}{$\mathbf{7 0 0}$} & AR & 0,5 & $2,21 \times 10^{-4}$ & 14,4 & 0,041 & 4,78 \\
& DA & 0,5 & $8,54 \times 10^{-5}$ & 16,3 & 0,028 & 4,67 \\
\hline
\end{tabular}




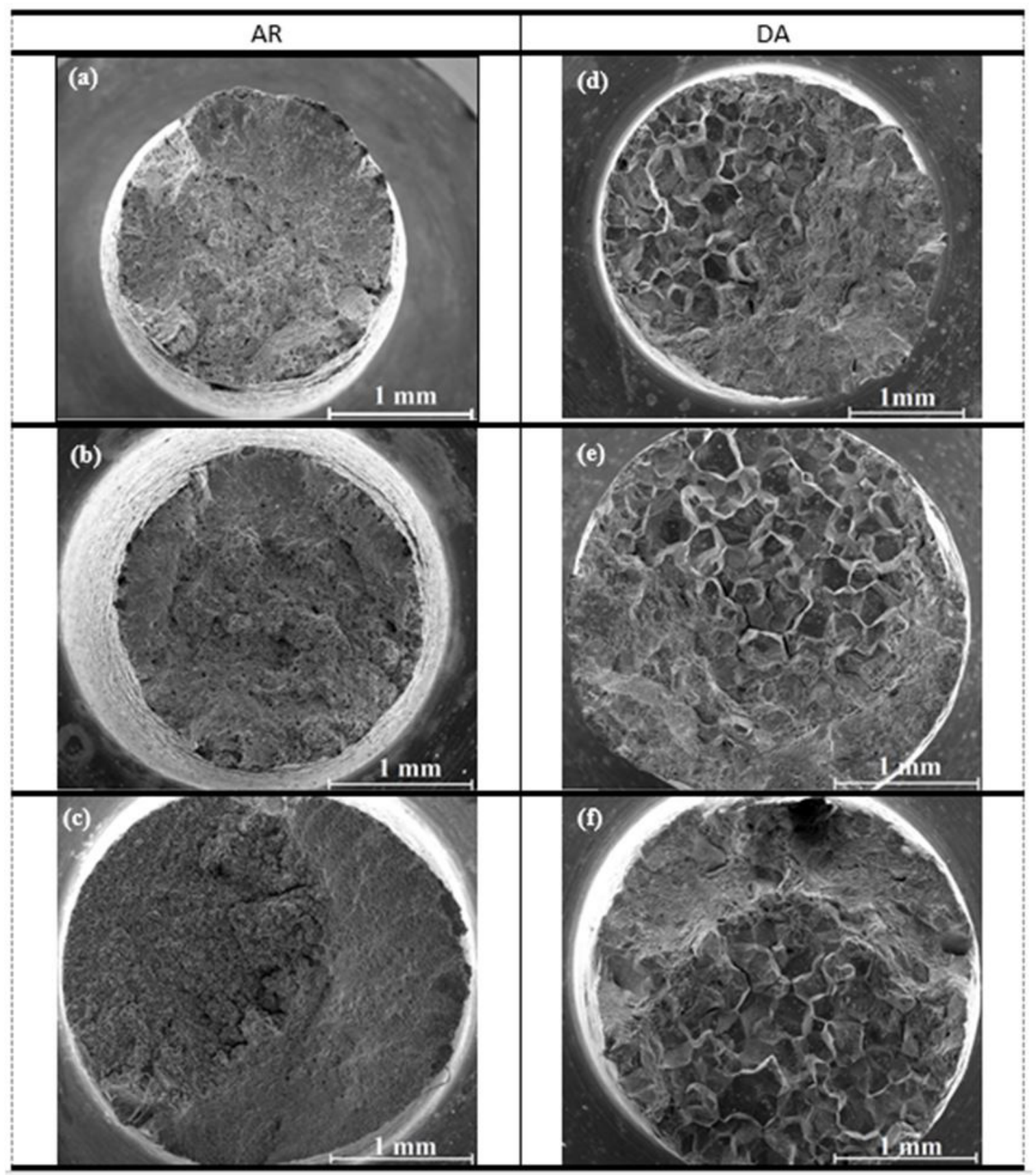

Figura 2. Micrografia da ruptura após ensaio de fluência sob tensão de $625 \mathrm{MPa}$. (a) AR $-650{ }^{\circ} \mathrm{C}$; (b) $\mathrm{AR}-675^{\circ} \mathrm{C}$; (c) $\mathrm{AR}-700{ }^{\circ} \mathrm{C}$; (d) $\mathrm{DA}$ $650{ }^{\circ} \mathrm{C}$; (e) DA $-675^{\circ} \mathrm{C}$ e (f) DA $-700^{\circ} \mathrm{C}$.

duplo envelhecimento houve um considerável aumento de precipitados sobre a matriz. Desta forma, as fraturas sugerem que o tratamento térmico de duplo envelhecimento gerou aumento das características frágil do material, provocando o aumento da região de fratura frágil, com presença de fratura intercristalina e grãos facetados. Essa diminuição de ductilidade, provocada pelo tratamento realizado, evidencia a precipitação de fases endurecedoras.

As análises microestruturais após o ensaio de fluência foram realizadas na avaliação do efeito promovido pela temperatura, tensão e tempo de exposição durante o ensaio, e são apresentados na Figura 3. Observou-se que para todas as condições, houve aumento dos tamanhos médio dos grãos, principalmente para a maior temperatura de ensaios de fluência a $700{ }^{\circ} \mathrm{C}$ (Figura 3c e 3f). A Tabela 2 apresenta os valores médios de tamanho de grão.

Em comparação aos dados da Tabela 1 e Tabela 2, o aumento da vida em fluência $\left(\dot{\varepsilon}_{s}\right)$ pode-se ter relação ao aumento do tamanho médio de grãos, já que esse fenômeno contribuiu para a redução no escorregamento ao longo do 

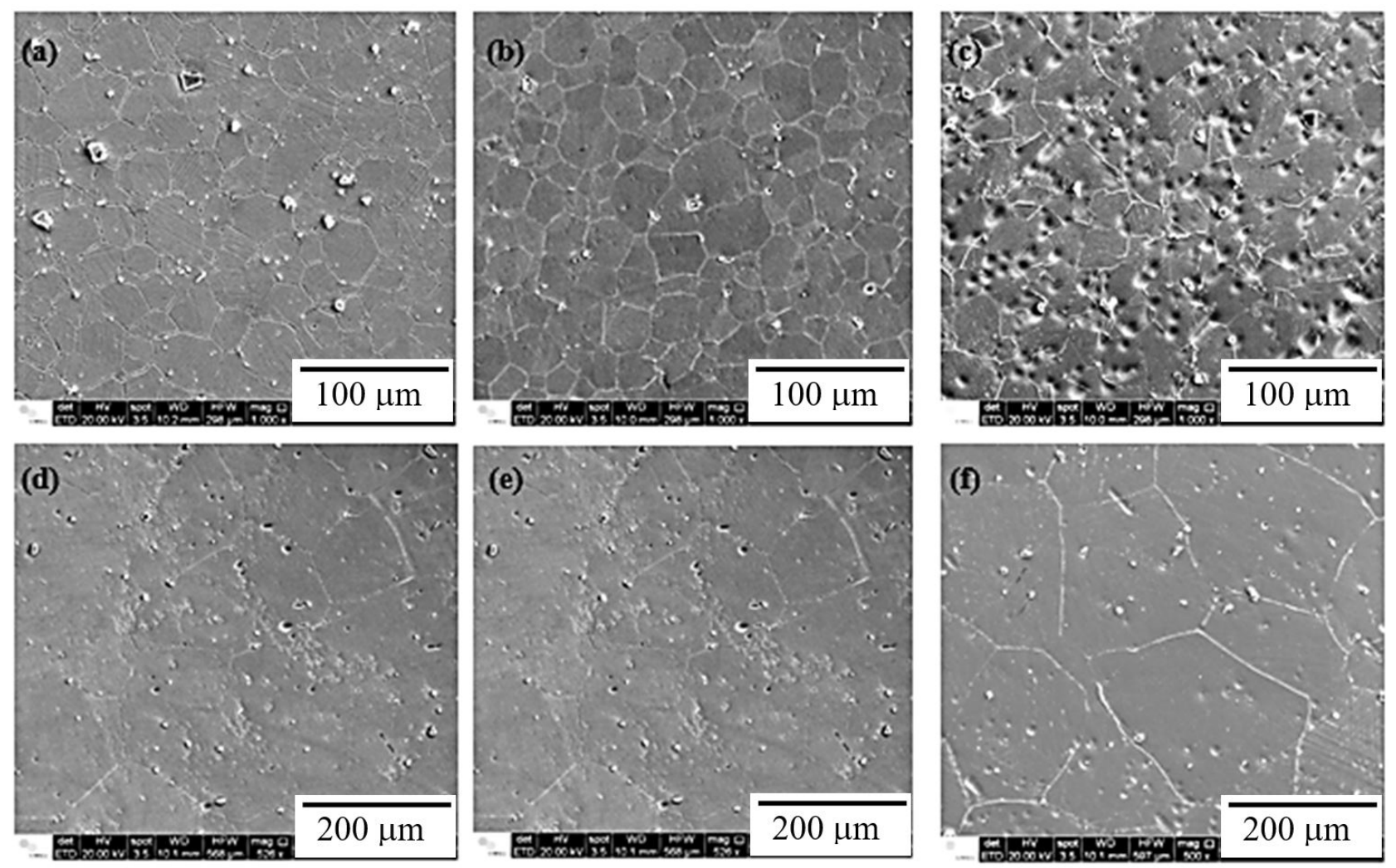

Figura 3. Microestrutura do Inconel 718 após ensaio de fluência na tensão de $625 \mathrm{MPa}$ por microscopia eletrônica de varredura. (a) AR - $650{ }^{\circ} \mathrm{C}$; (b) $\mathrm{AR}-675^{\circ} \mathrm{C}$; (c) $\mathrm{AR}-700{ }^{\circ} \mathrm{C}$; (d) DA $-650^{\circ} \mathrm{C}$; (e) DA $-675^{\circ} \mathrm{C}$ e (f) DA $-700^{\circ} \mathrm{C}$.

Tabela 2. Valores do tamanho de grão antes e após o ensaio de fluência a 650 MPa.

\begin{tabular}{ccccc}
\hline & \multirow{2}{*}{ Antes ensaio de fluência } & \multicolumn{3}{c}{ Após ensaio de fluência } \\
\cline { 3 - 5 } & & $\mathbf{6 5 0}^{\circ} \mathbf{C}$ & $\mathbf{6 7 5}^{\circ} \mathbf{C}$ & $\mathbf{7 0 0}^{\circ} \mathbf{C}$ \\
\hline AR & $8,60 \pm 0,07$ & $8,63 \pm 0,05$ & $8,67 \pm 0,05$ & $8,74 \pm 0,06$ \\
DA & $5,30 \pm 0,02$ & $5,32 \pm 0,03$ & $5,39 \pm 0,04$ & $5,52 \pm 0,03$ \\
\hline
\end{tabular}

contorno de grão e para a redução da oxidação [1]. Um dos mecanismos de deformação por fluência ocorre pelo deslizamento de contornos de grão [1], e assim a resistência à fluência está presente em materiais com tais características. O processo de crescimento de grão foi uma consequência da temperatura, visto que o crescimento dos grãos ocorre por difusão de curto alcance dos átomos de um lado do contorno para o outro. À medida que os grãos aumentaram de tamanho, a área total dos contornos diminuiu, produzindo, por consequência, uma redução na energia total. Dessa maneira, tem-se a força motriz para o crescimento dos grãos, no qual, os grãos maiores cresceram consumindo os menores.

As fases das amostras nas condições AR e DA puderam ser comprovadas pelas análises de difratometria de raios $\mathrm{X}$ (DRX) apresentados na Figura 4. Os resultados mostraram a presença de matriz gama $(\gamma-\mathrm{CFC})$ de níquel, como uma solução sólida, com picos sobrepostos de fase gama linha $\left(\gamma^{\prime}-\mathrm{CFC}\right)$, tanto para as amostras AR quanto para DA. A não detecção de outras fases pelo DRX, possivelmente ocorreu devido sua baixa fração volumétrica [19]. Um fator indicativo das modificações microestruturais, causadas pelo tratamento de duplo envelhecimento está no parâmetro de rede, em que se observou uma diminuição do parâmetro de rede da matriz de $0,3607 \mathrm{~nm}$ para $0,3600 \mathrm{~nm}$, desenvolvido via software PowderCell [20]. Uma possível explicação para a redução nos parâmetros de rede pode estar no fato de que os elementos de liga, que antes estavam em solução na matriz $\gamma$ foram expulsos, por difusão, para formar outras fases [21]. Análises de DRX após ensaio de fluência evidenciaram a precipitação de fases endurecedoras formadas durante a fluência.

Sabe-se que o tempo de exposição do material submetido ao ensaio de fluência, usualmente promove precipitações, e pode levar ao equilíbrio de algumas fases existentes [21]. Observou-se nos espectros a presença dos picos da matriz austenítica do níquel mais o precipitado gama linha $\left(\gamma+\gamma^{\prime}\right)$, assim como, previamente encontrado nas amostras antes da fluência. No entanto, o tempo e a temperatura de exposição em fluência favoreceram a deteç̧ão de outros picos, tais como picos de carbonetos (MC) e da 

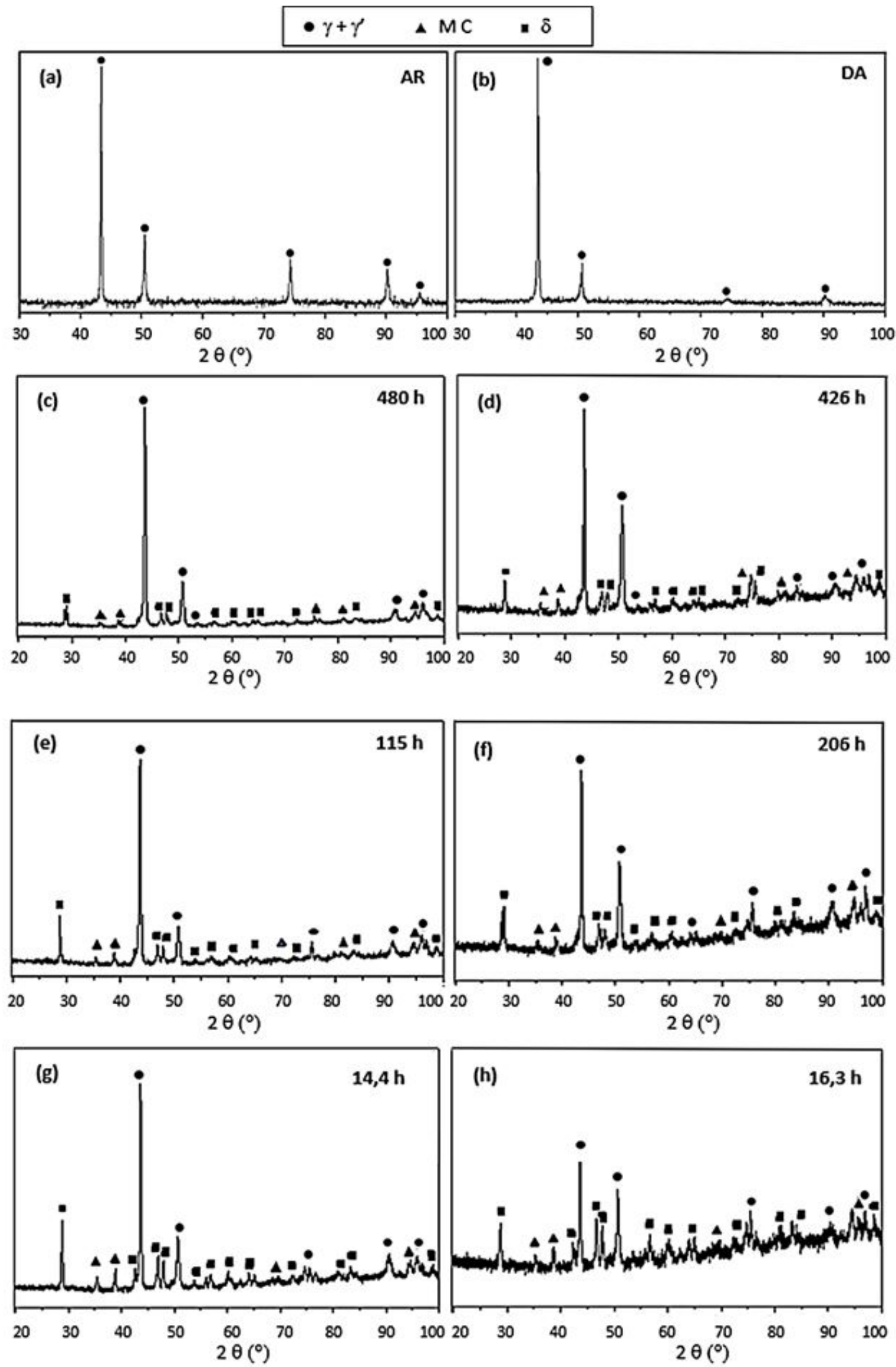

Figura 4. Difratogramas de raios X da superliga Inconel 718. (a) AR; (b) DA; (c) Exposto por 480 h; (d) Exposto por 426 h; (e) Exposto por 115 h; (f) Exposto por 206 h; (g) Exposto por 14,4 h e (h) Exposto por 16,3 h 
Tabela 3. Valores de microdureza Vickers das amostras de Inconel 718 após ensaio de fluência a $650 \mathrm{MPa}$.

\begin{tabular}{|c|c|c|}
\hline \multicolumn{2}{|c|}{ Amostra } & \multirow{2}{*}{$\begin{array}{c}\text { Microdureza (HV) } \\
387,92 \pm 18,74\end{array}$} \\
\hline $700^{\circ} \mathrm{C}$ & $\mathrm{AR}$ & \\
\hline & DA & $457,68 \pm 9,72$ \\
\hline \multirow[t]{2}{*}{$675^{\circ} \mathrm{C}$} & $\mathrm{AR}$ & $394,59 \pm 10,59$ \\
\hline & DA & $413,02 \pm 6,68$ \\
\hline \multirow[t]{2}{*}{$650^{\circ} \mathrm{C}$} & $\mathrm{AR}$ & $403,98 \pm 11,51$ \\
\hline & DA & $421,68 \pm 11,23$ \\
\hline
\end{tabular}

fase $\delta[19,22,23]$. A presença dessas fases favoreceu o tipo de fratura frágil observado pela fractografia (Figura 2), onde para as amostras DA observaram-se um considerável aumento de precipitados sobre a matriz. Essa diminuição de ductilidade, provocada pelo tratamento realizado, evidenciou a precipitação de fases endurecedoras na liga, assim como demonstrado pela técnica de DRX.

Os valores médios de microdureza Vickers da amostra de Inconel 718 antes do ensaio de fluência para as amostras AR foram de 240,94 $\pm 9,71 \mathrm{HV}$, e para as amostras DA foram de 469,10 $\pm 18,94 \mathrm{HV}$. Os valores encontrados no presente trabalho estão de acordo com a literatura [24] que reportou valores na faixa de 202,23 e 401,63 HV para o Inconel 718 e para o mesmo tratamento térmico de duplo envelhecimento em condições semelhantes ao realizado neste trabalho.

$\mathrm{O}$ aumento na dureza da amostra tratada por duplo envelhecimento é um indício da efetividade do tratamento térmico realizado, no qual, objetivou-se o endurecimento da liga pela precipitação de fases endurecedoras, como a fase $\gamma^{\prime}$ e $\gamma^{\prime \prime}$, que são responsáveis pelo aumento da resistência mecânica nas superligas Inconel 718.

A Tabela 3 apresenta os valores de microdureza após o ensaio de fluência.

Para as amostras AR os valores de dureza Vickers são superiores quando comparada as amostras AR após ensaio de fluência. A temperatura, a tensão, e o tempo dos ensaios de fluência serviram como tratamento térmico, aumentando o tamanho de grão, favorecendo a precipitação de fases endurecedoras detectadas pelo DRX, tais como carbonetos (MC) e fase $\delta$, e aumentando a dureza do material mesmo sem tratamento.

Os valores de microdureza Vickers para as amostras DA após ensaio de fluência apresentaram-se na mesma ordem de grandeza ou inferior em relação as amostras antes do ensaio. Possivelmente, esses resultados foram obtidos devido as amostras tratadas já estarem saturadas de precipitados de fases endurecedoras devido ao tratamento térmico. Desta forma, as condições aplicadas durante o ensaio de fluência promoveram o coalescimento dos precipitados e possível formação de fases deletérias [10,25], resultando na diminuição da dureza. Ainda assim, os valores de dureza das amostras tratadas são superiores quando comparadas com as amostras não tratadas nas mesmas condições após fluência.

\section{Conclusões}

No estudo do comportamento mecânico e microestrutural da superliga Inconel 718 submetidos a tratamento térmico de duplo envelhecimento sob ensaio de fluência pode-se concluir que:

- Os testes de fluência mostraram características do fenômeno com a presença de três regiões distintas, sendo que a diminuição da taxa de fluência, $\left(\dot{\varepsilon}_{S}\right)$ implicou no aumento de resistência à fluência da liga após o tratamento térmico de duplo envelhecimento, provavelmente devido a precipitação de fases endurecedoras;

- Os resultados de difratometria de raios X mostraram a presença de $\gamma^{\prime}$ e $\gamma$ " para as amostras antes do ensaio de fluência, mas para as amostras após o ensaio de fluência foi observada também a presença das fases $\mathrm{MC}$ e $\delta$;

- A resistência à fluência também foi mais significativa com o aumento da temperatura de ensaio, devido ao tamanho médio de grãos maiores após o tratamento térmico de duplo envelhecimento, além do crescimento de grão após o ensaio de fluência;

- Observou-se alteração dos valores de microdureza Vickers antes e após o ensaio de fluência, na qual o valor para a amostra AR aumentaram significativamente após o ensaio, e os valores para a amostra DA apresentaram-se na mesma ordem de grandeza ou inferior em relação as amostras antes do ensaio;

- O aumento dos valores de dureza, o aumento da resistência à fluência e o aumento significativamente da região de fratura frágil do material após o duplo envelhecimento foram evidências da eficácia do tratamento térmico, evidenciado pelo endurecimento por possível precipitação das fases endurecedoras $\gamma^{\prime}$ e $\gamma^{\prime \prime}$. No entanto, não há evidências da precipitação das fases $\gamma^{\prime}, \gamma^{\prime \prime}$ pelas análises via MEV, pois essas fases apenas podem ser observadas via microscopia eletrônica de transmissão [26-28].

\section{Agradecimentos}

À UNIFESP e ao LNNano pelo apoio e utilização de sua infraestrutura. O presente trabalho foi realizado com apoio da Coordenação de Aperfeiçoamento de Pessoal de Nível Superior - Brasil (CAPES) - Código de Financiamento 001.

\section{Referências}

1 Evans RW, Wilshire B. Introduction to creep. London: Springer Berlin Heidelberg; 1993. 
2 Galizoni BB, Couto AA, Reis DAP. Heat treatments effects on nickel-based superalloy inconel 713C. Metals. 2019;9(1):47.

3 De Oliveira MM, Couto AA, Almeida GFC, Reis DAP, De Lima NB, Baldan R. Mechanical behavior of inconel 625 at elevated temperatures. Metals. 2019;9(3):301.

4 Maj P, Zdunek J, Gizynski M, Mizera J, Kurzydlowski KJ. Statistical analysis of the Portevin-Le Chatelier effect in Inconel 718 at high temperature. Materials Science and Engineering A. 2014;619:158-164.

5 Martinolli K, Sugahara T, Reis DAP, de Moura C No, Hirschmann AC, Couto AA. Evaluation of Inconel 718 creep behavior. Defect and Diffusion Forum. 2012;326-328:525-529.

6 Sugahara T, Martinolli K, Reis DAP, Moura C No, Couto AA, Piorino F No, Barboza MJR. Creep behavior of the inconel 718 superalloy. Defect and Diffusion Forum. 2012;326-328:509-514.

7 Sims CT, Stoloff NS, Hagel WC. Superalloys II high temperature materials for aerospace and industrial power. New York, 1987.

8 Caliari FR, Candioto KCG, Couto AA, Nunes CÂ, Reis DAP. Effect of double aging heat treatment on the shortterm creep behavior of the Inconel 718. Journal of Materials Engineering and Performance. 2016;25(6):2307-2317.

9 Collier JP, Wong SH, Tien JK, Phillips JC, Tein JK. The effect of varying AI, Ti, and Nb content on the phase stability of INCONEL 718. Metallurgical Transactions A, 1988;19:1657-1666.

10 Alam T, Chaturvedi M, Ringer SP, Cairney JM. Precipitation and clustering in the early stages of ageing in Inconel 718. Materials Science and Engineering A. 2010;527(29-30):7770-7774.

11 You X, Tan Y, Shi S, Yang J-M. Effect of solution heat treatment on the precipitation behavior and strengthening mechanisms of electron beam smelted Inconel 718 superalloy. Materials Science and Engineering A. 2017;689(2):257-268.

12 Caliari FR, Candioto KCG, Reis DAP, Couto AA, De Moura C No, Nunes CA. Study of the mechanical behavior of an inconel 718 aged superalloy submitted to hot tensile tests. SAE Technical Papers; 2011;1-9.

13 ASTM International. ASTM E139-06 - Standard Test Methods for Conducting Creep, Creep-Rupture, and StressRupture Tests of Metallic Materials. West Conshohocken, PA: ASTM International; 2006.

14 Kuo CM, Yang YT, Bor HY, Wei CN, Tai CC. Aging effects on the microstructure and creep behavior of Inconel 718 superalloy. Materials Science and Engineering A. 2009;510-511:289-294.

15 Feng Y, Pan Z, Liang SY. Temperature prediction in Inconel 718 milling with microstructure evolution. International Journal of Advanced Manufacturing Technology. 2018;95(9-12):4607-4621.

16 Decker RF. The evolution of wrought age-hardenable superalloys. JOM. 2006;58(9):32-36.

17 Caron P, Khan T. Evolution of Ni-based superalloys for single crystal gas turbine blade applications. Aerospace Science and Technology. 1999;3(8):513-523.

18 Smith GD, Patel SJ. The role of niobium in wrought precipitation-hardened nickel-base alloys. In: Proceedings of the International Symposium on Superalloy Var. Derivatives; 2005; USA. USA: American Welding Society; 2005. p. 135-154.

19 Yeh AC, Lu KW, Kuo CM, Bor HY, Wei CN. Effect of serrated grain boundaries on the creep property of Inconel 718 superalloy. Materials Science and Engineering A. 2011;530(1):525-529.

20 Kraus W, Nolze G. Powder Cell - A program for the representation and manipulation of crystal structures and calculation of the resulting X-ray powder patterns. Journal of Applied Crystallography. 1996;29(3):301-303.

21 Garofalo F, Butrymowicz DB. Fundamentals of creep and creep-rupture in metals. Physics Today. 1966;19(5):100-102.

22 Liu WC, Yao M, Chen ZL, Wang SG. Niobium segregation in Inconel 718. Journal of Materials Science. 1999;34(11):2583-2586.

23 Slama C, Abdellaoui M. Structural characterization of the aged Inconel 718. Journal of Alloys and Compounds. 2000;306(1-2):277-284.

24 Caliari FR. Avaliação do comportamento em fluência da superliga Inconel 718 após duplo envelhecimento [dissertação]. São José dos Campos: ITA; 2012.

25 Whitmore L, Ahmadi MR, Guetaz L, Leitner H, Povoden-Karadeniz E, Stockinger M, et al. The microstructure of heat-treated nickel-based superalloy 718Plus. Materials Science and Engineering A. 2014;610:39-45.

26 Donachie MJ, Donachie SJ. Superalloys: a technical guide. 2nd ed. West Conshohocken, PA: ASTM International; 2002. 
27 Yadav PC, Sahu S, Subramaniam A, Shekhar S. Effect of heat-treatment on microstructural evolution and mechanical behaviour of severely deformed Inconel 718. Materials Science and Engineering A. 2018;715:295-306.

28 Candioto KCG, Caliari FR, Reis DAP, Couto AA, Nunes CA. Characterization of the superalloy Inconel 718 after double aging heat treatment. Mechanical and Materials Engineering of Modern Structure and Component Design. 2015;70:293-300.

Recebido: 17 Jun. 2021

Aceito: 21 Set. 2021 